\title{
Efficacy of nepafenac ophthalmic suspension $0.1 \%$ in improving clinical outcomes following cataract surgery in patients with diabetes: an analysis of two randomized studies
}

\author{
This article was published in the following Dove Press journal: \\ Clinical Ophthalmology \\ 29 May 2017 \\ Number of times this article has been viewed
}

\author{
Rishi P Singh' \\ Giovanni Staurenghi \\ Ayala Pollack ${ }^{3}$ \\ Adeniyi Adewale ${ }^{4}$ \\ Thomas MWalker ${ }^{4}$ \\ Dana Sager ${ }^{4}$ \\ Robert Lehmann ${ }^{5}$ \\ 'Cole Eye Institute, Cleveland \\ Clinic Foundation, Cleveland, $\mathrm{OH}$, \\ USA; ${ }^{2}$ Department of Biomedical \\ and Clinical Science Luigi Sacco, \\ Luigi Sacco Hospital, University of \\ Milan, Milan, Italy; ${ }^{3}$ Ophthalmology \\ Department, Kaplan Medical Center, \\ Rehovot, Israel; ${ }^{4}$ Alcon Research Ltd., \\ Fort Worth, TX, ${ }^{5}$ Lehmann Eye Center. \\ Nacogdoches, TX, USA
}

Objective: To assess the efficacy of nepafenac $0.1 \%$ ophthalmic suspension in improving the clinical outcomes following cataract surgery (CS) in patients with nonproliferative diabetic retinopathy.

Methods: In two similar multicenter, randomized studies, patients received either nepafenac $0.1 \%$ or vehicle, instilled three times daily starting a day prior to surgery and continuing for 90 days postoperatively. A post hoc analysis of these two studies was conducted to assess 1) the likelihood for development of postoperative macular edema (ME), based on the percentage of patients who developed ME ( $\geq 30 \%$ increase from preoperative baseline in central subfield macular thickness) within 90 days following CS and 2) best-corrected visual acuity (BCVA) endpoints, including the percentage of patients with a BCVA improvement of $\geq 15$ letters from preoperative baseline to Day 14 and maintained through Day 90. Results for individual studies and their pooled estimates (only visual acuity endpoints) are reported. Primary inference was based on odds ratio (OR).

Results: This post hoc analysis included 411 patients (nepafenac 0.1\%: 205; vehicle: 206). The incidence of postoperative ME within 90 days of CS was notably lower in the nepafenactreated patients than in vehicle-treated patients (study 1: $3.2 \%$ vs $16.7 \%$; OR $=0.2,95 \%$ confidence interval $[\mathrm{CI}]=0.1,0.5, P=0.001$; study $2: 5.0 \%$ vs $17.5 \%$; OR $=0.2,95 \% \mathrm{CI}=0.1$, $0.8, P=0.018)$. A higher percentage of nepafenac-treated patients than vehicle-treated patients gained $\geq 15$ letters from preoperative baseline to Day 14, which was maintained through Day 90 (study $1: 38.4 \%$ vs $21.4 \%$; OR $=2.4,95 \% \mathrm{CI}=1.4,4.2, P=0.003$; study $2: 35.0 \%$ vs $25.0 \%$; $\mathrm{OR}=1.6,95 \% \mathrm{CI}=0.8,3.2, P=0.172$; pooled: $37.1 \%$ vs $22.8 \%$; $\mathrm{OR}=2.0,95 \% \mathrm{CI}=1.3,3.1$, $P=0.001$ ). The odds of $>5$-letter and $>10$-letter loss in BCVA from postoperative Day 7 were higher in vehicle-treated than in nepafenac-treated patients.

Conclusion: These results support the clinical benefit of prophylactic use of nepafenac $0.1 \%$ for reducing the risk of postoperative ME and for improvement in BCVA outcomes following CS in patients with nonproliferative diabetic retinopathy.

Keywords: cataract surgery, nonproliferative diabetic retinopathy, nepafenac $0.1 \%$, postoperative macular edema, visual outcomes

\section{Introduction}

Postoperative macular edema (ME) following cataract surgery is an important cause for suboptimal visual outcomes, particularly in high-risk patients such as those with diabetes. ${ }^{1-8}$ A retrospective database study of 81,984 consecutive phacoemulsification 
cataract operations found the incidence of postoperative ME to be four times higher in patients with diabetes and the relative risk of postoperative ME to increase in proportion with the severity of diabetic retinopathy (DR). ${ }^{9}$

The prostaglandin-mediated inflammatory response triggered as a result of trauma during cataract surgery is considered to be an underlying cause for the development of ME. ${ }^{4}$ The effectiveness of topical anti-inflammatory agents, such as corticosteroids and nonsteroidal anti-inflammatory drugs (NSAIDs), that are commonly used for the management of postoperative ocular inflammation and pain, has also been studied for the prevention of postoperative ME. ${ }^{1,2,10,11}$

Nepafenac (Alcon Research Ltd, Fort Worth, TX, USA), a topical ocular NSAID, is available as an ophthalmic suspension in concentrations of $0.1 \%$ and $0.3 \% .^{12,13}$ Unlike other NSAIDs, nepafenac is a prodrug that is deaminated to its active metabolite (amfenac) in the ocular tissues. ${ }^{14,15}$ Both nepafenac and amfenac are potent inhibitors of cyclooxygenase isoforms, COX-1 and COX-2, and distribute rapidly in both the anterior and posterior segments of the eye. ${ }^{14-16}$ The high bioavailability of nepafenac in the posterior segment serves as a reservoir for hydrolysis to amfenac and accounts for nepafenac's prolonged activity in the ocular tissues. $^{14-16}$

The nepafenac $0.1 \%$ and $0.3 \%$ ophthalmic suspensions are the only NSAIDs approved in Europe for the reduction in the risk of postoperative ME associated with cataract surgery in patients with diabetes, with a recommended use for up to 60 days postoperatively. ${ }^{7}$ An extended treatment with nepafenac ophthalmic suspension $0.1 \%$ for 90 days after cataract surgery was shown to result in statistically significant and clinically relevant reduction in the risk of postoperative ME, and also a better maintenance of visual acuity (VA) in patients with nonproliferative diabetic retinopathy (NPDR). ${ }^{17,18}$

To gain additional understanding of the efficacy of nepafenac $0.1 \%$ in improving clinical outcomes following cataract surgery in patients with diabetes and NPDR, a post hoc analysis was conducted for data from the two individual nepafenac $0.1 \%$ studies as well as the pooled data from the two studies.

\section{Methods \\ Study design}

This post hoc analysis included data from two, multicenter, randomized, double-masked, controlled, parallel-group trials. One was a phase II study conducted between 2008 and 2010 at study centers in the USA (NCT00782717; study 1) and the other was a phase III study conducted between 2009 and 2010 at study centers in the USA, Europe, Middle East, and Asia Pacific (NCT00939276; study 2). The detailed study designs of the two studies have been published previously. ${ }^{17,18}$ Both the studies were conducted in accordance with the Good Clinical Practice and the Declaration of Helsinki. Each study protocol was reviewed and approved by an Independent Ethics Committee or an Institutional Review Board for each participating center. All patients provided written informed consent before entering the respective study.

The two trials were similar in design (Figure 1). Briefly, patients were administered either nepafenac $0.1 \%$ or vehicle, instilled three times daily in the study eye, on the day prior to cataract surgery, on the day of surgery, and for 90 days thereafter. An additional one drop of the study medication was administered 30-120 minutes prior to surgery. In all patients, regardless of the assigned study drug, a corticosteroid

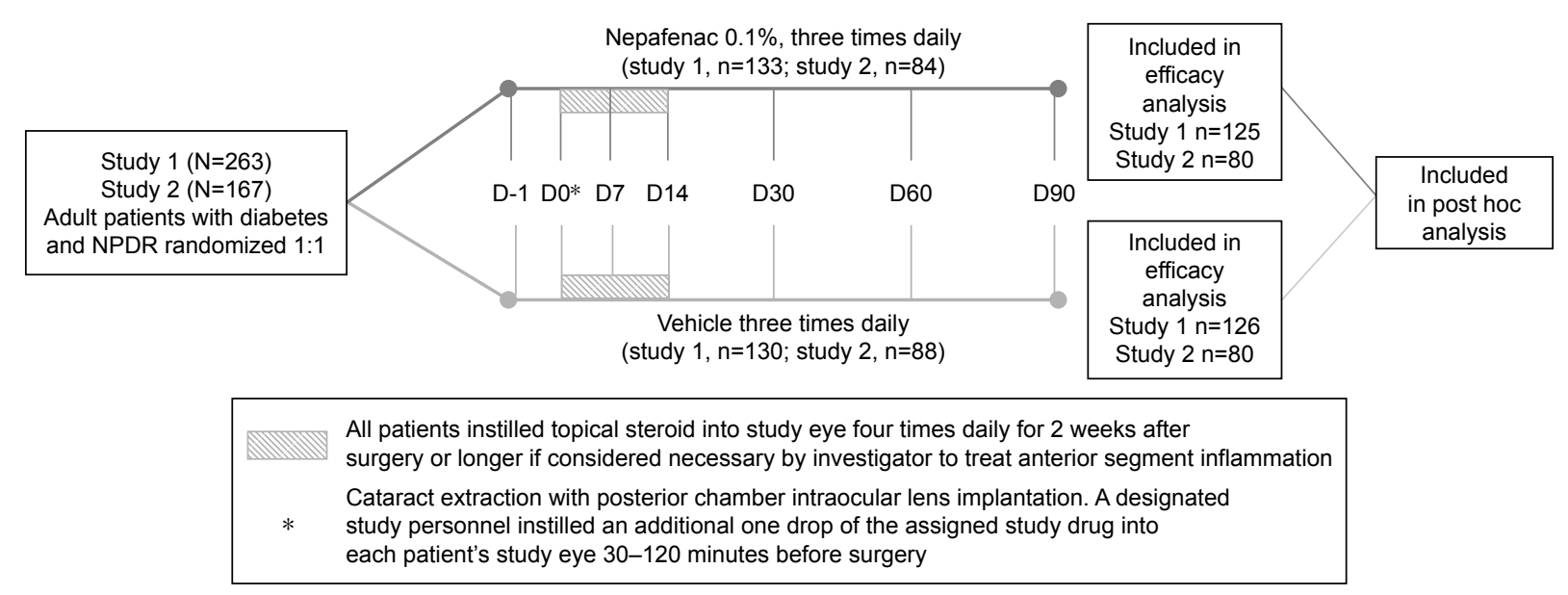

Figure I Study design.

Abbreviation: NPDR, nonproliferative diabetic retinopathy. 
(study 1: OMNIPRED ${ }^{\mathrm{TM}}$, prednisolone acetate ophthalmic suspension; study 2: TOBRADEX ${ }^{\circledR}$ tobramycin and dexamethasone ophthalmic suspension) was instilled into the study eye four times daily for 2 weeks postsurgery. There were six postsurgical visits (days $1,7,14,30,60$, and 90) in both studies. The only differences between the two studies were the eligibility requirements in central subfield macular thickness (CSMT) and the method for optical coherence tomography (OCT). In the phase II study, macular thickness was measured using time domain OCT and the ME cut-off was CSMT $\geq 250 \mu \mathrm{m}$, while in the phase III study, spectral domain OCT (SD-OCT) was used and the ME cut-off was CSMT $>320 \mu \mathrm{m} \cdot{ }^{17,18}$

In both studies, eligible patients were aged $\geq 18$ years and had a cataract that required extraction by phacoemulsification with planned implantation of the posterior chamber intraocular lens, and had diabetes (Type 1 or Type 2 ) and were diagnosed with NPDR (mild, moderate, or severe) as defined by the International Clinical Diabetic Retinopathy Disease Severity Scale. ${ }^{17,18}$ At least $50 \%$ of the randomized patients in each treatment arm had to have moderate or severe NPDR. Patients with pre-existing ME in the study eye were excluded.

\section{Post hoc analyses assessments}

The efficacy and safety data from the two individual studies have been published previously. ${ }^{17,18}$ In this post hoc analysis, the endpoints assessed in the individual studies were the following: the percentage of patients who developed ME (defined as $\geq 30 \%$ increase from preoperative baseline in CSMT) within 90 days following cataract surgery; the percentage of patients with a best-corrected visual acuity (BCVA) improvement of $\geq 15$ letters from preoperative baseline to Day 14 and maintained through Day 90; the percentage of patients with a BCVA improvement of $\geq 15$ letters from preoperative baseline to Day 90 and Day 60; the percentage with BCVA loss of $>5$ letters and $>10$ letters from Day 7 to any visit; and mean change from baseline in BCVA. The post hoc analysis of pooled data from the two studies only included the VA endpoints, since different OCT methods were used in the two studies for assessment of ME. There were no safety assessments in this post hoc analysis.

\section{Statistical analyses}

The post hoc efficacy analysis was conducted on the full analysis set which consisted of all patients who completed the implant surgery and had at least one on-therapy postsurgical visit. For the pooled analysis, the full analysis sets of the respective studies were pooled for each treatment arm.

A logistic regression model was employed that included treatment and retinopathy severity terms to compare odds of event outcomes. The primary inference for ME and BCVA endpoints was based on the odds ratio (OR). The estimated OR, associated $95 \%$ confidence intervals (CIs), and $P$-values were calculated. The percentage of patients with BCVA improvement of $\geq 15$ letters from preoperative baseline to Day 14 and maintained through Day 90 was based on a binary variable (positive outcome; negative outcome) which was derived using the change from preoperative baseline in BCVA at Day 14, Day 30, Day 60, and Day 90. A positive outcome required that BCVA improvement from preoperative baseline be $\geq 15$ letters at all four visits (days 14, 30, 60, and 90). Any response short of BCVA improvement of $\geq 15$ letters at all four visits was considered a negative outcome. A patient with BCVA data missing at one or more than one visit was considered as a negative outcome. For the mean change from baseline, the estimated difference in means by visit and the associated 95\% CIs were provided. Descriptive statistics were used to summarize baseline and demographic characteristics, and data were presented by treatment group.

\section{Results}

The baseline and demographic characteristics of all patients included in the analysis are shown in Table 1 . The pooled population included 411 patients (nepafenac 0.1\% group: 205; vehicle: 206). Overall, the two treatment groups were well balanced. The mean age of patients was 67 years, $\sim 46 \%$ were males, and $>80 \%$ were white. In both treatment groups, $>50 \%$ patients had moderate NPDR and $38 \%$ patients had mild NPDR (Table 1).

\section{ME endpoint}

As previously reported, in both studies, a significantly lower percentage of patients in nepafenac $0.1 \%$-treated group developed $\mathrm{ME}$ relative to those in the vehicle group (study $1: 3.2 \%$ vs $16.7 \%, P=0.001$; study $2: 5.0 \%$ vs $17.5 \%$, $P=0.012) .{ }^{17,18}$ In this post hoc analysis, the odds of developing postoperative ME within 90 days of cataract surgery were observed to be notably lower in nepafenac $0.1 \%$-treated group than in the vehicle-treated group in the two studies (study 1: $\mathrm{OR}=0.2,95 \% \mathrm{CI}=0.1,0.5, P=0.001$; study 2 : $\mathrm{OR}=0.2 ; 95 \% \mathrm{CI}=0.1,0.8, P=0.018$ ). No pooled analysis was performed for this endpoint due to differences in the OCT methodology used in the two studies. 
Table I Demographic and baseline characteristics of patients in each treatment group by individual study and pooled data (FAS)

\begin{tabular}{|c|c|c|c|c|c|c|}
\hline & \multicolumn{2}{|l|}{ Study I } & \multicolumn{2}{|l|}{ Study 2} & \multicolumn{2}{|l|}{ Pooled } \\
\hline & $\begin{array}{l}\text { Nepafenac } \\
0.1 \%, n=126\end{array}$ & $\begin{array}{l}\text { Vehicle, } \\
n=\mid 25\end{array}$ & $\begin{array}{l}\text { Nepafenac } \\
0.1 \%, n=80\end{array}$ & $\begin{array}{l}\text { Vehicle, } \\
\mathrm{n}=\mathbf{8 0}\end{array}$ & $\begin{array}{l}\text { Nepafenac } \\
\mathbf{0 . 1 \% , n = 2 0 5}\end{array}$ & $\begin{array}{l}\text { Vehicle, } \\
\mathrm{n}=206\end{array}$ \\
\hline Mean age, years $( \pm S D)$ & $66.6(9.3)$ & $66.4(9.7)$ & $68.1(8.6)$ & $69.4(7.7)$ & $67.2(9.0)$ & $67.5(9.0)$ \\
\hline Male, n (\%) & $42(33.6)$ & $5 I(40.5)$ & $51(63.8)$ & $44(55.0)$ & $93(45.4)$ & $95(46.1)$ \\
\hline \multicolumn{7}{|l|}{ Race, n (\%) } \\
\hline White & $97(77.6)$ & $108(85.7)$ & $69(86.3)$ & $71(88.8)$ & $166(81.0)$ & $179(86.9)$ \\
\hline Black/African-American & $21(16.8)$ & $13(10.3)$ & I (I.3) & $0(0)$ & $22(10.7)$ & $13(6.3)$ \\
\hline American Indian/Alaska Native & $0(0)$ & $\mathrm{I}(0.8)$ & - & - & $0(0)$ & $\mathrm{I}(0.5)$ \\
\hline Asian & $7(5.6)$ & I (0.8) & $6(7.5)$ & $5(6.3)$ & $13(6.3)$ & $6(2.9)$ \\
\hline Native Hawaiian/other Pacific Islander & $0(0)$ & $0(0)$ & $2(2.5)$ & $2(2.5)$ & $2(1.0)$ & $2(1.0)$ \\
\hline Other & $0(0)$ & $3(2.4)$ & $2(2.5)$ & $2(2.5)$ & $2(1.0)$ & $5(2.4)$ \\
\hline CSMT, mean $( \pm S D)$ & $197.9(26.6)$ & $203.6(24.8)$ & $268.8(29.0)$ & $276.8(23.2)$ & $225.6(44.2)$ & $232.0(43.1)$ \\
\hline Mean BCVA $( \pm S D)$ & $68.2(9.3)$ & $66.7(14.1)$ & $62.5(14.5)$ & $64.3(14.1)$ & 65.9 (11.9) & $65.8(14.1)$ \\
\hline \multicolumn{7}{|l|}{ Retinopathy severity, n (\%) } \\
\hline Mild & $19(15.2)$ & $26(20.6)$ & $58(72.5)$ & $57(7 \mid .3)$ & 77 (37.6) & $83(40.3)$ \\
\hline Moderate & $89(7 \mid .2)$ & $86(68.3)$ & $21(26.3)$ & $22(27.5)$ & $110(53.7)$ & $108(52.4)$ \\
\hline Severe & $17(13.6)$ & I4 (II.I) & I (I.3) & I (I.3) & I 8 (8.8) & I5 (7.3) \\
\hline
\end{tabular}

Abbreviations: BCVA, best-corrected visual acuity; CSMT, central subfield macular thickness; FAS, full analysis set; SD, standard deviation.

\section{BCVA endpoints}

As shown in Figure 2, a higher percentage of nepafenac $0.1 \%$ treated patients had a BCVA improvement of $\geq 15$ letters from preoperative baseline to Day 14 and maintained through Day 90, compared with vehicle (study 1: $38.4 \%$ vs $21.4 \%$, $P=0.003$; study $2: 35.0 \%$ vs $25.0 \%, P=0.172$ ). The analysis of pooled data from the two studies also showed that treatment with nepafenac $0.1 \%$ was associated with a higher odds of achieving a BCVA improvement of $\geq 15$ letters from preoperative baseline to Day 14 maintained through Day 90 , as compared to vehicle $(37.1 \%$ vs $22.8 \%$; OR $=2.0$, $95 \% \mathrm{CI}=1.3,3.1 ; P=0.001$ ).
As shown in Figure 3, while the percentage of patients with an improvement in VA of $\geq 15$ letters from preoperative baseline to Day 90 was higher in the nepafenac $0.1 \%$ group than in the vehicle group, the difference between the groups was notable in study $1(55.2 \%$ vs $34.9 \%, P=0.001)$, but not in study $2(47.5 \%$ vs $35 \%, P=0.111)$. However, in the pooled estimate, treatment with nepafenac $0.1 \%$ was associated with an increased odds of improvement in VA of $\geq 15$ letters from preoperative baseline to Day 90, compared with vehicle (52.2\% vs $35 \%$; OR $=2.0,95 \% \mathrm{CI}=1.4,3.0 ; P<0.001)$.

Similarly, the percentage of patients with an improvement in VA of $\geq 15$ letters from preoperative baseline

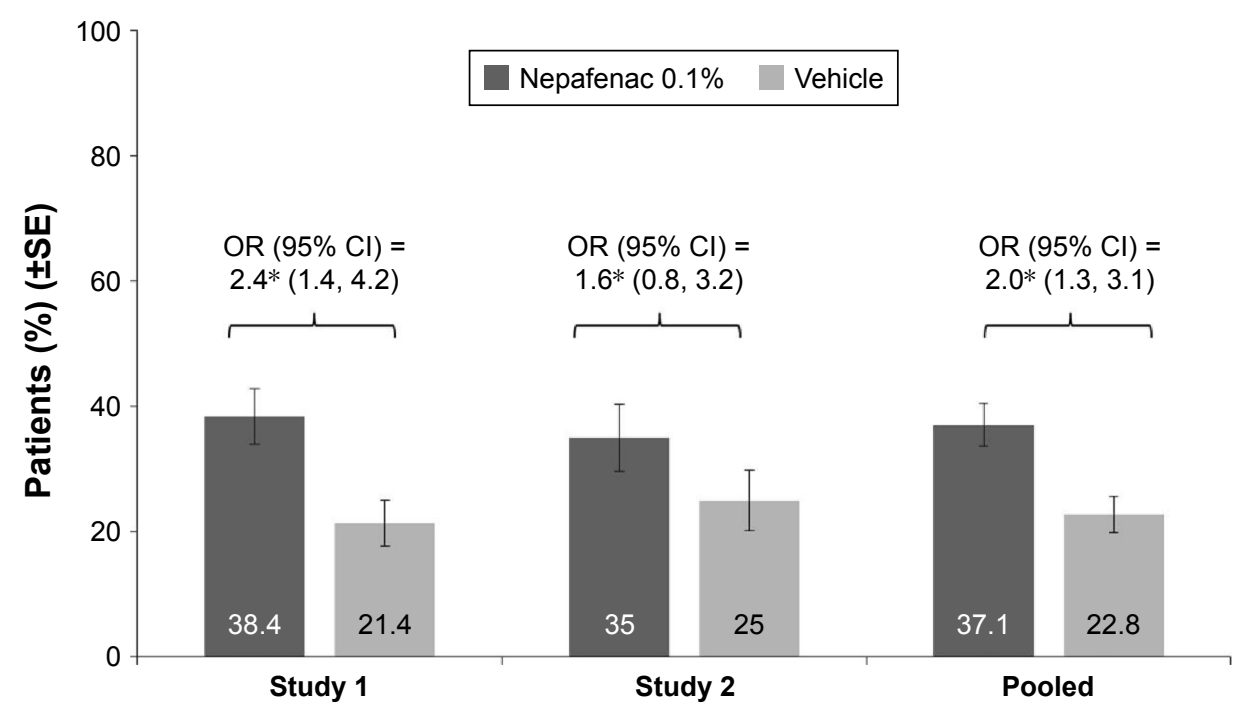

Figure 2 Percentage of patients with BCVA improvement of $\geq 15$ letters from preoperative baseline to Day 14 and maintained through Day 90 in each treatment group by individual study and pooled data (FAS).

Notes: P-value (study I: 0.003 ; study 2: 0.172; pooled: 0.001 ); $* P<0.05$.

Abbreviations: BCVA, best-corrected visual acuity; $\mathrm{Cl}$, confidence interval; FAS, full analysis set; OR, odds ratio; SE, standard error. 


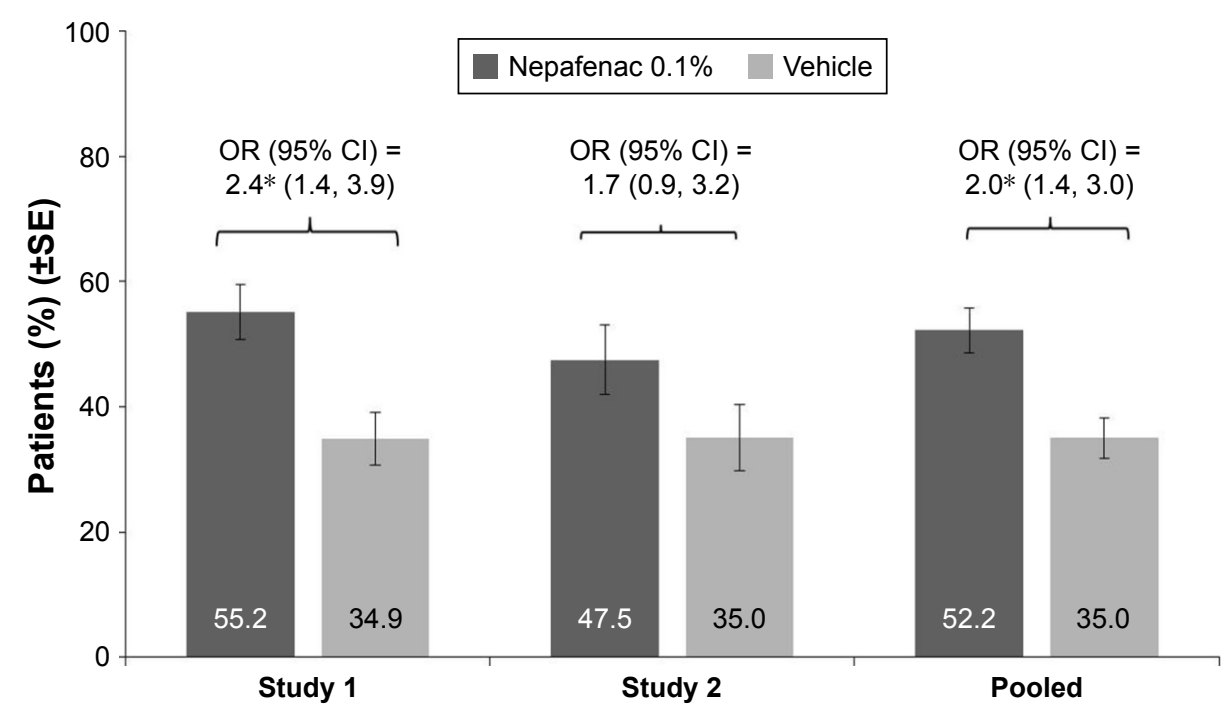

Figure 3 Percentage of patients with BCVA improvement of $\geq 15$ letters from preoperative baseline and maintained through Day 90 in each treatment group by individual study and pooled data (FAS).

Notes: $P$-value (study I: 0.001 ; study 2: 0.1 II; pooled: $<0.001$ ); $* P<0.05$.

Abbreviations: BCVA, best-corrected visual acuity; $\mathrm{Cl}$, confidence interval; FAS, full analysis set; OR, odds ratio; SE, standard error.

to Day 60 was higher in the nepafenac $0.1 \%$ group than in vehicle, the difference between treatment groups was notable in study $1(P=0.046)$, but not in study $2(P=0.272$; Figure 4). In the pooled estimate, treatment with nepafenac $0.1 \%$ was associated with an increased odds of improvement in VA of $\geq 15$ letters from preoperative baseline to Day 60 $(\mathrm{OR}=1.6 ; 95 \% \mathrm{CI}=1.1,2.3 ; P=0.025$; Figure 4$)$.

The percentage of patients with a loss in VA of $>5$ letters or $>10$ letters from Day 7 to any visit was more in the vehicle than in the nepafenac $0.1 \%$ group. For both these BCVA endpoints, the odds for postoperative loss in VA were notably lower with nepafenac $0.1 \%$ compared with vehicle in study 1 and in the analysis of pooled data from the two studies $(P<0.001)$, but not in study $2(P>0.05$; Table 2$)$.

The mean changes in BCVA for patients in nepafenac $0.1 \%$ - and vehicle-treated groups at all postoperative visits are shown in Table 3. The mean change from baseline in BCVA at all postoperative visits up to Day 90 was greater in the nepafenac $0.1 \%$ group than in the vehicle group, although the difference between the two treatment groups was notable only at Day 60 (in study 1 and in the analysis of pooled data from the two studies, but not in study 2; Table 3).

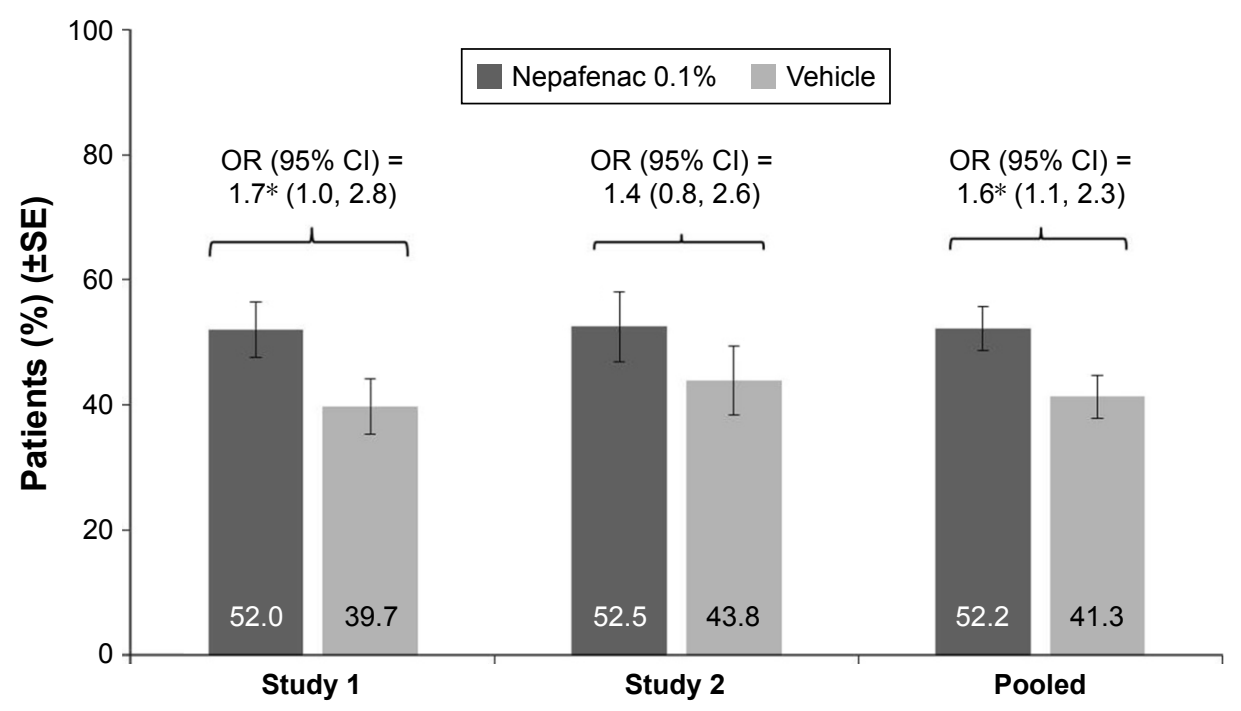

Figure 4 Percentage of patients with BCVA improvement of $\geq 15$ letters from preoperative baseline and maintained through Day 60 in each treatment group by individual study and pooled data (FAS).

Notes: P-value (study I: 0.046; study 2: 0.272; pooled: 0.025); $* P<0.05$.

Abbreviations: BCVA, best-corrected visual acuity; $\mathrm{Cl}$, confidence interval; FAS, full analysis set; OR, odds ratio; SE, standard error. 
Table 2 Summary of BCVA outcomes in each treatment group by individual study and pooled data (FAS)

\begin{tabular}{|c|c|c|c|c|}
\hline Endpoint & $\begin{array}{l}\text { Nepafenac } \\
0.1 \%, \text { n (\%) }\end{array}$ & $\begin{array}{l}\text { Vehicle, } \\
\text { n (\%) }\end{array}$ & OR (95\% Cl) & $P$-value \\
\hline Study I & $\mathrm{n}=125$ & $n=126$ & & \\
\hline $\begin{array}{l}\text { BCVA improvement of } \geq 15 \text { letters from preoperative baseline to Day } 14 \\
\text { and maintained through Day } 90\end{array}$ & $48(38.4)$ & $27(2 \mid .4)$ & $2.4(1.4,4.2)$ & $0.003 *$ \\
\hline BCVA improvement of $\geq 15$ letters from preoperative baseline to Day 90 & $69(55.2)$ & $44(34.9)$ & $2.4(1.4,3.9)$ & $0.001 *$ \\
\hline BCVA improvement of $\geq 15$ letters from preoperative baseline to Day 60 & $65(52.0)$ & $50(39.7)$ & $1.7(1.0,2.8)$ & $0.046 *$ \\
\hline BCVA $>5$-letter loss from Day 7 to any visit & $19(15.2)$ & $54(42.9)$ & $0.2(0.1,0.4)$ & $<0.00 I^{*}$ \\
\hline BCVA $>10$-letter loss from Day 7 to any visit & $9(7.2)$ & $36(28.6)$ & $0.2(0.1,0.4)$ & $<0.00 I^{*}$ \\
\hline Study 2 & $\mathrm{n}=80$ & $\mathrm{n}=80$ & & \\
\hline $\begin{array}{l}\text { BCVA improvement of } \geq 15 \text { letters from preoperative baseline to Day } 14 \\
\text { and maintained through Day } 90\end{array}$ & $28(35.0)$ & $20(25.0)$ & $1.6(0.8,3.2)$ & 0.172 \\
\hline BCVA improvement of $\geq 15$ letters from preoperative baseline to Day 90 & $38(47.5)$ & $28(35.0)$ & $1.7(0.9,3.2)$ & 0.111 \\
\hline BCVA improvement of $\geq 15$ letters from preoperative baseline to Day 60 & $42(52.5)$ & $35(43.8)$ & I.4 $(0.8,2.6)$ & 0.272 \\
\hline BCVA $>5$-letter loss from Day 7 to any visit & $36(45.0)$ & $43(53.8)$ & $0.7(0.4,1.3)$ & 0.274 \\
\hline BCVA $>10$-letter loss from Day 7 to any visit & $30(37.5)$ & $37(46.3)$ & $0.7(0.4,1.3)$ & 0.269 \\
\hline Pooled & $\mathrm{n}=205$ & $\mathrm{n}=206$ & & \\
\hline $\begin{array}{l}\text { BCVA improvement of } \geq 15 \text { letters from preoperative baseline to Day } 14 \\
\text { and maintained through Day } 90\end{array}$ & $76(37.1)$ & $47(22.8)$ & $2.0(1.3,3.1)$ & $0.001 *$ \\
\hline BCVA improvement of $\geq 15$ letters from preoperative baseline to Day 90 & $107(52.2)$ & $72(35.0)$ & $2.0(1.4,3.0)$ & $<0.00 I^{*}$ \\
\hline BCVA improvement of $\geq 15$ letters from preoperative baseline to Day 60 & $107(52.2)$ & $85(4 \mid .3)$ & I.6 (I.I, 2.3) & $0.025^{*}$ \\
\hline BCVA $>5$-letter loss from Day 7 to any visit & $55(26.8)$ & $97(47.1)$ & $0.4(0.3,0.6)$ & $<0.00 I^{*}$ \\
\hline BCVA $>10$-letter loss from Day 7 to any visit & $39(19.0)$ & $73(35.4)$ & $0.4(0.3,0.7)$ & $<0.00 I^{*}$ \\
\hline
\end{tabular}

Note: $* p<0.05$.

Abbreviations: BCVA, best-corrected visual acuity; $\mathrm{Cl}$, confidence interval; FAS, full analysis set; OR, odds ratio.

\section{Discussion}

The results of this post hoc analyses corroborated the findings from the two individual studies, that prophylactic treatment with nepafenac $0.1 \%$, initiated 1 day prior to and continued for 90 days after the cataract surgery, reduces the risk of postoperative ME in patients with diabetes and NPDR, compared to vehicle. Treatment with nepafenac $0.1 \%$ was found to lower the odds of postoperative ME by
$80 \%$ in these patients, compared with vehicle. This finding is consistent with the primary analysis of data in the two studies that had shown the incidence of postoperative ME to be three- to five fold lower in the nepafenac $0.1 \%$ group than in the vehicle group. ${ }^{17,18}$ Recently, the nepafenac $0.3 \%$ ophthalmic suspension administered once daily for 90 days postoperatively has also been shown to reduce the risk of postoperative ME in patients with NPDR. ${ }^{19}$

Table 3 Mean BCVA at baseline and at each postoperative visit in each treatment group by individual study and pooled data (FAS)

\begin{tabular}{|c|c|c|c|c|c|c|c|c|c|}
\hline \multirow[t]{2}{*}{ BCVA } & \multicolumn{3}{|l|}{ Study I } & \multicolumn{3}{|l|}{ Study 2} & \multicolumn{3}{|l|}{ Pooled data } \\
\hline & $\begin{array}{l}\text { Nepafenac } \\
0.1 \%,(n=125)\end{array}$ & $\begin{array}{l}\text { Vehicle, } \\
(n=\mid 26)\end{array}$ & $P$-value & $\begin{array}{l}\text { Nepafenac } \\
0.1 \%,(n=80)\end{array}$ & $\begin{array}{l}\text { Vehicle, } \\
(n=80)\end{array}$ & $P$-value & $\begin{array}{l}\text { Nepafenac } \\
0.1 \%,(n=205)\end{array}$ & $\begin{array}{l}\text { Vehicle, } \\
(n=206)\end{array}$ & $P$-value \\
\hline \multicolumn{10}{|l|}{ Baseline BCVA } \\
\hline Mean (SD) & $68.2(9.3)$ & $66.7(14.1)$ & & $62.5(14.5)$ & $64.3(14.1)$ & & 65.9 (11.9) & $65.8(14.1)$ & \\
\hline Day 7 (n) & 125 & 121 & & 80 & 80 & & 205 & 201 & \\
\hline Mean (SD) & $81.3(7.5)$ & $80.4(7.3)$ & 0.412 & $77.5(12.0)$ & $79.3(8.0)$ & 0.325 & $79.8(9.7)$ & $80.0(7.6)$ & 0.856 \\
\hline Day I4 (n) & 125 & 123 & & 78 & 80 & & 203 & 203 & \\
\hline Mean (SD) & $82.7(7.4)$ & $80.1(7.6)$ & $0.004^{*}$ & $78.6(11.1)$ & $79.0(7.7)$ & 0.825 & $81.1(9.2)$ & $79.6(7.7)$ & 0.073 \\
\hline Day 30 (n) & 123 & 115 & & 74 & 73 & & 197 & 188 & \\
\hline Mean (SD) & $82.4(9.2)$ & $81.3(6.7)$ & 0.196 & $79.3(13.5)$ & $76.2(18.2)$ & 0.233 & $81.3(11.1)$ & $79.3(12.7)$ & 0.078 \\
\hline Day 60 (n) & 117 & 111 & & 68 & 66 & & 185 & 177 & \\
\hline Mean (SD) & $83.9(5.9)$ & $82.0(6.2)$ & 0.055 & $80.7(13.1)$ & $79.0(12.3)$ & 0.253 & $82.7(9.3)$ & $80.8(9.0)$ & $0.047^{*}$ \\
\hline Day 90 (n) & 119 & 103 & & 66 & 54 & & 185 & 157 & \\
\hline Mean (SD) & $84.2(6.3)$ & $82.7(5.8)$ & 0.092 & $76.3(21.7)$ & $81.3(7.7)$ & 0.208 & $81.4(14.3)$ & $82.2(6.5)$ & 0.784 \\
\hline
\end{tabular}

Note: $* p<0.05$.

Abbreviations: BCVA, best-corrected visual acuity; FAS, full analysis set; SD, standard deviation. 
Furthermore, in study 1 and in pooled analysis, compared to vehicle-treated patients, a notably higher percentage of nepafenac $0.1 \%$-treated patients had a faster recovery in VA, with a clinically meaningful improvement ( $\geq 15$ letters gain) in BCVA from preoperative baseline to postoperative Day 14, which was sustained throughout the study period (Day 90). Higher percentage of patients in the vehicle group had a $>5$-letter and $>10$-letter loss after postoperative Day 7 , compared with the nepafenac $0.1 \%$ group. Overall, for all BCVA endpoints in this study, patients treated with nepafenac $0.1 \%$ showed better VA improvements, consistent with results from previous studies. ${ }^{20,21}$

One of the quality measures of cataract surgery is the percentage of patients achieving a VA of $20 / 40$ or better (distance or near) within 90 days following an uneventful cataract extraction. ${ }^{22}$ While good visual prognosis is reported in diabetic patients after cataract surgery, the percentage of patients, especially those with DR, achieving better than $20 / 40$ vision is lower than that reported for nondiabetic patients. ${ }^{23-25}$ Suboptimal visual function severely impacts the quality of life; therefore, early restoration of vision after cataract surgery is highly desirable to the patients. ${ }^{26}$ Patients with DR are more prone to inflammatory effects, due to a compromised blood-retinal barrier function that can result in exacerbation of ME or retinopathy progression. ${ }^{27-31}$ Therefore, DR patients require careful management of postoperative inflammation to ensure stable vision, and thus, a preventive approach would help in reducing the risk of visual impairment due to ME.

Contrasting reports exist regarding the beneficial role of NSAIDs in reducing the risk of postoperative ME after cataract surgery. ${ }^{1,2,10,11,28-41}$ However, a comparison of results across studies is limited due to factors such as differences in the definition of ME used, the method used for detecting $\mathrm{ME}$ (fluorescein angiography vs OCT), duration of treatment, concurrent medication used, and the patient population included. Very few of these studies have assessed both postoperative $\mathrm{ME}$ and BCVA outcomes.

NSAIDs have been reported to be more effective than topical corticosteroids in reducing/preventing postoperative ME after an uneventful cataract surgery. ${ }^{1,11}$ It was observed in a systematic review of randomized clinical trials that in patients with diabetes, a combination of topical NSAIDs and corticosteroids significantly reduced the odds of developing postoperative ME after cataract surgery than corticosteroids alone. ${ }^{1}$ Kim et al have suggested that this is likely due to the additive effect of the two anti-inflammatory drugs. ${ }^{2}$ However, results from the two nepafenac $0.1 \%$ studies reported here suggest that the reduction in risk of postoperative ME observed in the two studies is primarily due to nepafenac $0.1 \%$ treatment. Although all patients had received additional corticosteroid treatment, the ME and VA findings were in favor of the group receiving nepafenac $0.1 \%$ than vehicle at all postoperative time points in both the studies. This is supported by another study that directly compared nepafenac with a topical corticosteroid in low-risk patients; after cataract extraction, nepafenac was found to be more effective in preventing cystoid ME and leading to more rapid visual recovery. ${ }^{20}$

A limitation of the results presented in this study was that all analyses were post hoc. Thus, claims to statistical significance were not made. Furthermore, study 2 was terminated early, with only $67 \%$ of the planned sample size enrolled due to patient recruitment difficulties. The reduced sample size in study 2 could have contributed to the relatively weaker results for VA endpoints, compared to study 1 results. However, VA outcomes in study 2 were numerically in favor of nepafenac $0.1 \%$ suspension than vehicle and, thus, directionally consistent with study 1 . Though study 1 and study 2 had similar inclusion criteria, they differed in the OCT technique used: time domain OCT vs SD-OCT. Due to greater sensitivity of SD-OCT to detect retinal anatomy, a high percentage of screened patients, such as even those with small cystoid abnormalities/more severe retinopathy, were excluded, which severely limited the enrollment in study 2.

Safety was not assessed as part of this post hoc analysis. However, the safety profile of nepafenac has been established across several studies. The adverse events reported in the two nepafenac $0.1 \%$ studies included in this post hoc analyses were consistent with those reported in previous nepafenac studies. ${ }^{20,21,31}$ Overall, no new safety signals were identified with the extended use of nepafenac $0.1 \%$ for up to 90 days following cataract surgery in either study..$^{17,18}$

\section{Conclusion}

These results support the clinical benefit with the prophylactic use of nepafenac suspension $0.1 \%$, beginning preoperatively, in reducing the risk of postoperative $\mathrm{ME}$ and for early and sustained improvement in BCVA outcomes following an uneventful cataract surgery in patients with diabetes and NPDR.

\section{Acknowledgments}

The study was funded by Alcon Research Ltd (now a Novartis company), Fort Worth, TX, USA. Medical writing support for 
this manuscript was provided by Shivani Vadapalli (Novartis Healthcare Pvt Ltd, Hyderabad, India).

\section{Disclosure}

Rishi P Singh is a consultant for Alcon, Regeneron, Genentech, Zeiss, and Shire and conducts sponsored research for Genentech/Roche, Regeneron, and Apellis. Giovanni Staurenghi reports personal fees from Novartis, personal fees from Alcon, personal fees from Bayer, personal fees from Allergan, personal fees from Boehringer Ingelheim, personal fees from Genentech, personal fees from Roche, grants and personal fees from Zeiss Meditec, grants and personal fees from Heidelberg Engineering, grants and personal fees from Optos, and grants and personal fees from Centervue outside the submitted work. Ayala Pollack has received research grant from Alcon, Bayer, Neovista, Novartis, Ophthotech, Regeneron, Quark, and Santen. Robert Lehmann is a consultant for Alcon and conducts sponsored research for Baush \& Lomb, AMO, WaveTech, Omerous, and AVS. Adeniyi Adewale, Thomas Walker, and Dana Sager are employees of Alcon Research Ltd, Fort Worth, TX. The authors report no other conflicts of interest in this work.

\section{References}

1. Wielders LH, Lambermont VA, Schouten JS, et al. Prevention of cystoid macular edema after cataract surgery in non-diabetic and diabetic patients: a systematic review and meta-analysis. Am J Ophthalmol. 2015;160(5):968-981.

2. Kim SJ, Schoenberger SD, Thorne JE, Ehlers JP, Yeh S, Bakri SJ. Topical nonsteroidal anti-inflammatory drugs and cataract surgery: a report by the American Academy of Ophthalmology. Ophthalmology. 2015;122(11):2159-2168.

3. Henderson BA, Kim JY, Ament CS, Ferrufino-Ponce ZK, Grabowska A, Cremers SL. Clinical pseudophakic cystoid macular edema. Risk factors for development and duration after treatment. J Cataract Refract Surg. 2007;33(9):1550-1558.

4. Benitah NR, Arroyo JG. Pseudophakic cystoid macular edema. Int Ophtalmol Clin. 2010;50(1):139-153.

5. Eriksson U, Alm A, Bjarnhall G, Granstam E, Matsson AW. Macular edema and visual outcome following cataract surgery in patients with diabetic retinopathy and controls. Graefes Arch Clin Exp Ophthalmol. 2011;249(3):349-359.

6. Krepler K, Biowski R, Schrey S, Jandrasits K, Wedrich A. Cataract surgery in patients with diabetic retinopathy: visual outcome, progression of diabetic retinopathy, and incidence of diabetic macular oedema. Graefes Arch Clin Exp Ophthalmol. 2002;240(9):735-738.

7. Baker CW, Almukhtar T, Bressler NM, et al; Diabetic Retinopathy Clinical Research Network Authors/Writing Committee. Macular edema after cataract surgery in eyes without preoperative central involved diabetic macular edema. JAMA Ophthalmol. 2013;131(7):870-879.

8. Dowler JGF, Sehmi KS, Hykin PG, Hamilton AM. The natural history of macular edema after cataract surgery in diabetes. Ophthalmology. 1999;106(4):663-668.

9. Chu CJ, Johnston RL, Buscombe C, Sallam AB, Mohamed Q, Yang YC; United Kingdom Pseudophakic Macular Edema Study Group Ophthalmology. Risk factors and incidence of macular edema after cataract surgery: a database study of 81984 eyes. Ophthalmology. 2016; 123(2):316-323.
10. Rossetti L, Chaudhuri J, Dickersin K. Medical prophylaxis and treatment of cystoid macular edema after cataract surgery. The results of a meta-analysis. Ophthalmology. 1998;105(3):397-405.

11. Kessel L, Tendal B, Jørgensen KJ, et al. Post-cataract prevention of inflammation and macular edema by steroid and nonsteroidal antiinflammatory eye drops: a systematic review. Ophthalmology. 2014; 121(10):1915-1924.

12. European Medical Agency Assessment Report: Nevenac EMA/ CHMP/167525/2016. Available from: http://www.ema.europa.eu/docs/ en_GB/document_library/EPAR_-_Assessment_Report_-_Variation/ human/000818/WC500212717.pdf. Accessed October 5, 2016.

13. ILEVRO ${ }^{\mathrm{TM}}$ (nepafenac ophthalmic suspension $0.3 \%$ ) [package insert]. Fort Worth, TX, Alcon Laboratories, Inc.; 2014. Available from: http:// ecatalog.alcon.com/PI/Ilevro_us_en.pdf. Accessed April 27, 2016.

14. Ke TL, Graff G, Spellman JM, Yanni JM. Nepafenac, a unique nonsteroidal prodrug with potential utility in the treatment of trauma-induced ocular inflammation: II. In vitro bioactivation and permeation of external ocular barriers. Inflammation. 2000;24(4):371-384.

15. Walters T, Raizman M, Ernest P, Gayton J, Lehmann R. In vivo pharmacokinetics and in vitro pharmacodynamics of nepafenac, amfenac, ketorolac, and bromfenac. J Cataract Refract Surg. 2007; 33(9):1539-1545.

16. Chastain JE, Sanders ME, Curtis MA, et al. Distribution of topical ocular nepafenac and its active metabolite amfenac to the posterior segment of the eye. Exp Eye Res. 2016;145:58-67.

17. Singh R, Alpern L, Jaffe GJ, et al. Evaluation of nepafenac in prevention of macular edema following cataract surgery in patients with diabetic retinopathy. Clin Ophthalmol. 2012;6:1259-1269.

18. Pollack A, Staurenghi G, Sager D, Mukesh B, Reiser H, Singh R. Prospective randomized clinical trial to evaluate the safety and efficacy of nepafenac treatment for the prevention of macular edema associated with cataract surgery in patients with diabetic retinopathy. Br J Ophthalmol. 2016:1-5.

19. Singh R, Lehmann R, Martel J, et al. Nepafenac $0.3 \%$ following cataract surgery in patients with diabetic retinopathy: results of two randomized Phase 3 studies. Ophthalmology. Epub 2017 Mar 4.

20. Miyake K, Ota I, Miyake G, Numaga J. Nepafenac $0.1 \%$ versus fluorometholone $0.1 \%$ for preventing cystoid macular edema after cataract surgery. J Cataract Refract Surg. 2011;37(9):1581-1588.

21. Hariprasad SM, Callanan D, Gainey S, He YG, Warren K. Cystoid and diabetic macular edema treated with nepafenac $0.1 \%$. J Ocul Pharmacol Ther. 2007;23(6):585-590.

22. American Medical Association. 2016 Registry Individual Measure Flow- Measure \#191 (NQF 0565): Cataracts: 20/40 or Better Visual Acuity within 90 Days Following Cataract Surgery - National Quality Strategy Domain: Effective Clinical Care. Available from: http://www.mdinteractive.com/files/uploaded/file/CMS2016/2016_ PQRS_Measure_191_11_17_2015.pdf. Accessed on May 6, 2016.

23. Mittra RA, Borrillo JL, Dev S, Mieler WF, Koenig SB. Retinopathy progression and visual outcomes after phacoemulsification in patients with diabetes mellitus. Arch Ophthalmol. 2000;118(7):912-917.

24. Baker CW, Almukhtar T, Bressler NM, et al. Macular edema after cataract surgery in eyes without preoperative central-involved diabetic macular edema. JAMA Ophthalmol. 2013;131(7):870-879.

25. Lundström M, Manning S, Barry P, Stenevi U, Henry Y, Rosen P. Visual outcome of cataract surgery; study from the European registry of quality outcomes for cataract and refractive surgery. $J$ Cataract Refract Surg. 2013;39(5):673-679.

26. Morris D, Fraser SD, Gray C. Cataract surgery and quality of life implications. Clin Interv Aging. 2007;2(1):105-108.

27. Ferguson VMG, Spalton DJ. Continued breakdown of the blood aqueous barrier following cataract surgery. Br J Ophthalmol. 1992; 76(8):453-456.

28. Pollack A, Leiba H, Bukelman A, Oliver M. Cystoid macular oedema following cataract extraction in patients with diabetes. Br JOphthalmol. 1992;76(4):221-224. 
29. Henricsson M, Heijl A, Janzon L. Diabetic retinopathy before and after cataract surgery. Br J Ophthalmol. 1996;80(9):789-793.

30. Zaczek A, Olivestedt G, Zetterstrom C. Visual outcome after phacoemulsification and IOL implantation in diabetic patients. $\mathrm{Br} J$ Ophthalmol. 1999;83(9):1036-1041.

31. Wolf EJ, Braunstein A, Shih C, Braunstein RE. Incidence of visually significant pseudophakic macular edema after uneventful phacoemulsification in patients treated with nepafenac. J Cataract Refract Surg. 2007;33(9):1546-1549.

32. Mathys KC, Cohen KL. Impact of nepafenac $0.1 \%$ on macular thickness and postoperative visual acuity after cataract surgery in patients at low risk for cystoid macular oedema. Eye (Lond). 2010;24(1):90-96.

33. Almeida DRP, Khan Z, Xing L, et al. Prophylactic nepafenac and ketorolac versus placebo in preventing postoperative macular edema after uneventful phacoemulsification. J Cataract Refract Surg. 2012; 38(9):1537-1543.

34. Tzelikis PF, Vieira M, Hida Wt, et al. Comparison of ketorolac $0.4 \%$ and nepafenac $0.1 \%$ for the prevention of cystoid macular oedema after phacoemulsification: prospective placebo-controlled randomised study. Br J Ophthalmol. 2015;99(5):654-658.

35. Almeida DRP, Johnson D, Hollands H, et al. Effect of prophylactic nonsteroidal anti-inflammatory drugs on cystoid macular edema assessed using optical coherence tomography quantification of total macular volume after cataract surgery. J Cataract Refract Surg. 2008; 34(1):64-69.
36. Asano S, Miyake K, Ota I, et al. Reducing angiographic cystoid macular edema and blood-aqueous barrier disruption after small-incision phacoemulsification and foldable intraocular lens implantation: multicenter prospective randomized comparison of topical diclofenac $0.1 \%$ and betamethasone 0.1\%. J Cataract Refract Surg. 2008;34(1):57-63.

37. Hirneiss C, Neubauer AS, Kampik A, Schonfeld CL. Comparison of prednisolone $1 \%$, rimexolone $1 \%$ and ketorolac tromethamine $0.5 \%$ after cataract extraction: a prospective, randomized, double-masked study. Graefes Arch Clin Exp Ophthalmol. 2005;243(8):768-773.

38. Holzer MP, Solomon KD, Sandoval HP, Vroman DT. Comparison of ketorolac tromethamine $0.5 \%$ and loteprednol etabonate $0.5 \%$ for inflammation after phacoemulsification: prospective randomized double-masked study. J Cataract Refract Surg. 2002;28(1):93-99.

39. Wang QW, Yao K, Xu W, et al. Bromfenac sodium $0.1 \%$, fluorometholone $0.1 \%$ and dexamethasone $0.1 \%$ for control of ocular inflammation and prevention of cystoid macular edema after phacoemulsification. Ophthalmologica. 2013;229(4):187-194.

40. Donnenfeld ED, Holland EJ, Solomon KD, et al. A multicenter randomized controlled fellow eye trial of pulse-dosed difluprednate $0.05 \%$ versus prednisolone acetate $1 \%$ in cataract surgery. Am J Ophthalmol. 2011;152(4):609-617.

41. Donnenfeld ED, Perry HD, Wittpenn JR, Solomon R, Nattis A, Chou T. Preoperative ketorolac tromethamine $0.4 \%$ in phacoemulsification outcomes: pharmacokinetic response curve. J Cataract Refract Surg. 2006;32(9):1474-1482.
Clinical Ophthalmology

\section{Publish your work in this journal}

Clinical Ophthalmology is an international, peer-reviewed journal covering all subspecialties within ophthalmology. Key topics include: Optometry; Visual science; Pharmacology and drug therapy in eye diseases; Basic Sciences; Primary and Secondary eye care; Patient Safety and Quality of Care Improvements. This journal is indexed on

Submit your manuscript here: http://www.dovepress.com/clinical-ophthalmology-journal

\section{Dovepress}

PubMed Central and CAS, and is the official journal of The Society of Clinical Ophthalmology (SCO). The manuscript management system is completely online and includes a very quick and fair peer-review system, which is all easy to use. Visit http://www.dovepress.com/ testimonials.php to read real quotes from published authors. 